\title{
EL PRINCIPIO DE INTERDICCIÓN DE LA COMPENSACIÓN OCULTA O FINANCIACIÓN SILENCIOSA
}

\author{
Ernesto SaLVAdOR Fuentes \\ Graduado en Derecho y Administración \\ y Dirección de Empresas por la UCM \\ ernestosalv@gmail.com
}

\begin{abstract}
RESUMEN
El propósito de este artículo es profundizar en las transferencias de fondos entre los distintos niveles de Hacienda y vislumbrar su encaje en el ordenamiento jurídico español, con especial referencia a la Constitución y a la LOFCA. Además, se analizarán los casos que se han dado en España, cómo se ha actuado y si existe algún caso en la actualidad. Se hará un breve repaso sobre el difícil caso del régimen de concierto y convenio del País Vasco y Navarra.
\end{abstract}

Palabras clave: principio constitucional, LOFCA, principio de solidaridad, transferencia de fondos, Administraciones tributarias, compensación financiera.

\section{ABSTRACT}

The aim of this article is a deep study of fund transfers within the several tax office rates and to foresee to fit them in the Spanish legal system, particularly in the Constitution and the Organic Law for Local Communities Funding. We will also look into the cases that Spain has produced as well as into the measures taken and also to see whether there is currently any such case. We will go through the special case of concert regime and agreements for the Basque Country and Navarra.

Keywords: Constitutional principle, Organic Law for Local Communities, fund transfer, tax compensation.

\section{ZUSSAMENFASSUNG}

Die Absicht dieses Artikels ist es, das Thema der Überweisungen von Finanzmitteln zwischen den verschiedenen Ebenen des Finanzamts eingehend zu behandeln und zu durchleuchten, wie sich diese zur spanischen Rechtsordnung verhalten. Hierbei soll besonders auf die Spanische Verfassung und auf die LOFCA (Verfassungsgesetz zur Finanzierung der Autonomen Regionen Spaniens) Bezug genommen werden. Außerdem werden diejenigen Fälle untersucht, die sich in Spanien ereignet haben; wie sie behandelt wurden und ob derzeit ein neuer Fall existiert. Es wird eine kurze Zusammenfassung zur Übereinkunft und Vereinbarung mit dem Baskenland und der Autonomen Region Navarra dargeboten.

Schlüsselwörter: Verfassungsprinzip, LOFCA, Solidaritätsprinzip, Überweisung von Finanzmitteln, Finanzverwaltungsbehörden, Finanzausgleich. 
SUMARIO: I. EL PRINCIPIO DE INTERDICCIÓN DE LA COMPENSACIÓN OCULTA O FINANCIACIÓN SILENCIOSA. CONCEPTO Y ORIGEN.-1. Principios afectados y relación constitucional.-2. Especial implicación de la Ley Orgánica de Financiación de las Comunidades Autónomas.-3. Descripción doctrinal.-II. CUESTIONES PRÁCTICAS. ANÁLISIS A LA LUZ DE LA DOCTRINA Y LA JURISPRUDENCIA.-1. Las concesiones, el sistema de financiación de peaje en sombra y el Impuesto sobre Bienes Inmuebles.-2. Las concesiones y el Impuesto sobre Transmisiones Patrimoniales Onerosas. - 3. Tipos incrementados del Impuesto sobre los Actos Jurídicos Documentados en el caso de renuncia al Impuesto sobre el Valor Añadido.-4. Inclusión en la prorrata, dentro del Impuesto sobre el Valor Añadido, de las subvenciones y su relación con la Sexta Directiva.-5. Apuntes al régimen de concierto y convenio del País Vasco y Navarra.-III. CONCLUSIONES.-IV. BIBLIOGRAFÍA.

\section{EL PRINCIPIO DE INTERDICCIÓN DE LA COMPENSACIÓN OCULTA O FINANCIACIÓN SILENCIOSA. CONCEPTO Y ORIGEN LEGISLATIVO}

\section{Principios afectados y relación constitucional}

Respecto a la compensación financiera, en puridad podemos decir que en un sistema unitario puro no serían necesarias las medidas de compensación, puesto que el sistema impositivo, legal y financiero, al igual que la prestación de servicios, los gastos, etc., estarían centralizados. Sin embargo, los sistemas federales tienen regiones autónomas dispares, con distintas capacidades económicas y financieras, que dan sentido a las medidas de compensación. La compensación financiera puede definirse como un sistema de transferencias financieras orientadas al equilibrio de la capacidad presupuestaria o de los resultados económicos de los diferentes niveles territoriales en un sistema federal; con ello se trata de garantizar una distribución homogénea de los servicios públicos y la presión fiscal ${ }^{1}$.

El desequilibrio que se da entre los ingresos y los gastos, la heterogeneidad de las distintas regiones y sus diferentes capacidades económicas provoca que sea necesaria una compensación financiera entre ellas, lo que exige la adopción de mecanismos que permitan remediar dichas disparidades, de modo que los territorios puedan prestar convenientemente los servicios. Esto es lo que se denomina la perecaución ${ }^{2}$, o mejor dicho

${ }^{1}$ Comunicación de la Comisión al Consejo y al Parlamento Europeo, de 4 de febrero de 1983 (libro verde), anexo II.

2 Del francés «pérécuatión» o del italiano «perequazione». 
-y como lo califica la doctrina alemana y el art. 158 de la Ley Fundamental-, la compensación financiera ${ }^{3}$.

Una vez que se ha esbozado el concepto de compensación financiera quisiéramos centrarnos en los principios afectados por el principio de interdicción de la compensación oculta o financiación silenciosa y su relación constitucional.

Entre los principios rectores que tienen mayor trascendencia y vinculación con el principio que aquí tratamos podemos destacar los siguientes: principio de solidaridad, neutralidad, territorialidad, lealtad institucional o federal y de coordinación con la Hacienda estatal. Sobre algunos de ellos es conveniente sentar una serie de bases para posteriormente afrontar su relación con el principio que aquí nos afecta:

- El principio de solidaridad tiene una importancia capital y efectiva en el ordenamiento constitucional español, sobre todo en materia financiera. Este principio está consagrado en los arts. 2 y 138 de la Carta Constitucional. El Estado debe velar por el establecimiento de un equilibrio económico, adecuado y justo, entre las diversas partes del territorio español y los Estatutos de las distintas Comunidades Autónomas no podrán implicar, en ningún caso, privilegios económicos o sociales ${ }^{4}$.

- El derecho a la igualdad en el aspecto tributario se consagra en los arts. 2.1 y 9 de la Ley Orgánica de Financiación de las Comunidades Autónomas (en adelante, LOFCA) y también se proclama el derecho a la igualdad territorial (art. 138.2 CE).

- El principio de territorialidad se traduce en la imposibilidad de que sean gravados elementos patrimoniales situados fuera del territorio de la respectiva Comunidad, así como tampoco los rendimientos o gastos realizados fuera de esta ${ }^{5}$.

- El principio de neutralidad o unidad de mercado está íntimamente ligado con el principio de igualdad y territorialidad. No se

${ }^{3}$ Para ahondar respecto al origen, descripción y tipos de la compensación financiera vid. R. FALCón y Tella, La compensación financiera interterritorial, Madrid, Congreso de los Diputados, 1986.

${ }^{4}$ R. FAlCÓN y TelLa, «Dos consecuencias del principio de interdicción constitucional de la compensación financiera silenciosa u oculta (Stille Finanzausgleicht) en el ITPAJD: las concesiones y los tipos incrementados de AJD en caso de renuncia a la exención de IVA», Quincena Fiscal, núm. 7 (2007), pp. 5-8.

5 J. E. Varona Alabern, 25 años de financiación autonómica, Santander, Universidad de Cantabria, 2005, pp. 89 y ss. 
podrán crear barreras aduaneras que supongan un obstáculo a la libre circulación de mercancías o servicios. También aparece en el art. 19.2 LOFCA abordando el aspecto referente a la ubicación de las empresas ${ }^{6}$.

Respecto al principio de solidaridad, debemos matizar que este principio tiene también una funcionalidad mucho más simple, esencial y primaria de la que hemos citado anteriormente — donde encontramos su núcleo-, como es la de lograr un buen funcionamiento de las estructuras públicas y una correcta articulación de las competencias. En definitiva, este principio dispone que los poderes públicos deben tener un comportamiento leal, aceptando las reglas del sistema y procurando su conservación ${ }^{7}$.

La Sentencia 64/1990 del Tribunal Constitucional (en adelante, STC), en su fundamento jurídico octavo, manifiesta: «A la vista de este principio y de las obligaciones que implica para todos los poderes públicos, es de vital importancia destacar que deben examinarse con el mayor rigor aquellas medidas que, por su objeto inmediato, parecen dirigidas a asegurar a una parte del territorio beneficios o ventajas a expensas de otros».

Junto a este principio de solidaridad existen otros como el principio de lealtad institucional, introducido por la Ley 4/1999, de 13 de enero, que modifica la Ley 30/1992, ahora derogada, y que en su exposición de motivos señala: «Como corolario del principio general de buena fe aplicado al Derecho público se incluye también el principio de lealtad institucional como criterio rector que facilite la colaboración y la cooperación entre las diferentes Administraciones Públicas, recogiendo los pronunciamientos del Tribunal Constitucional».

La STC 247/2007, de 12 de diciembre, fue muy esclarecedora en este sentido al señalar que: «Conviene recordar que, de acuerdo con la STC 25/1981, fundamento jurídico tercero, el principio de lealtad constitucional requiere que las decisiones tomadas por todos los entes territoriales, y, en especial, por el Estado y por las Comunidades Autónomas, tengan como referencia necesaria la satisfacción de los intereses generales y que, en consecuencia, no se tomen decisiones que puedan menoscabar o per-

${ }^{6}$ J. LASARTE, Manual general de Derecho financiero, t. IV, Sistema tributario autonómico y local, Granada, Comares, 1996, p. 48, y M. FernánDEZ JunQUeRA, «Límites de las Cortes Generales al establecimiento de tributos por las Comunidades Autónomas», en Las Cortes Generales, vol. II, Madrid, Ministerio de Economía y Hacienda-Instituto de Estudios Fiscales, 1987, p. 1041.

7 S. Muñoz Machado, Derecho público de las Comunidades Autónomas. t. I, 2.a ed., Madrid, Iustel, 2007, pp. 215-220. 
turbar dichos intereses, de modo que esta orientación sea tenida en cuenta, incluso al gestionar los intereses propios» ${ }^{8}$.

Junto a estos debemos destacar dos principios más, como son el de coordinación con la Hacienda estatal (art. 156.1 CE) y con las Administraciones del Estado (art. 103.1 CE).

Además de los principios expuestos existen otros más específicos, como el art. 150.2, que versa sobre la coordinación de las competencias legislativas, exponiendo lo siguente: «El Estado podrá transferir o delegar en las Comunidades Autónomas, mediante ley orgánica, facultades correspondientes a materias de titularidad estatal que por su propia naturaleza sean susceptibles de transferencia o delegación. La ley preverá en cada caso la correspondiente transferencia de medios financieros, así como las formas de control que se reserve el Estado». Por tanto, es esencial que se prevean los suficientes medios financieros para poder transferir o delegar competencias a las Comunidades Autónomas?.

\section{Especial implicación de la Ley Orgánica de Financiación de las Comunidades Autónomas}

Para evitar una invasión de competencias frente a las corporaciones locales, el art. 6.3 LOFCA dispone una norma similar a la del art. 150 de la Constitución, pero esta vez en la relación entre la Comunidad Autónoma y las corporaciones locales.

Además de cumplir el art. 6 LOFCA, las Comunidades Autónomas, al establecer sus propios impuestos, deberán respetar los elementos patrimoniales situados y los rendimientos originados fuera de su demarcación territorial. En consonancia con los arts. 157.2 y 139 CE, estos tributos no podrán suponer un impedimento para la libre circulación de personas, mercancías, servicios y capitales ni afectar de manera efectiva a la fijación de residencia ni, por supuesto, suponer cargas trasladables a otras Comunidades (art. 9 LOFCA).

Se usará como criterio rector para atribuir los tributos cedidos a las Comunidades Autónomas el domicilio fiscal de los sujetos pasivos en los impuestos personales fijado en el art. 10 LOFCA. Para los tributos sobre

\footnotetext{
8 A. Palomar y J. Fuentes, Práctico administrativo (ibook), Vlex, 2014, apartado «Administración pública, régimen jurídico y relación entre administraciones».

9 R. FALCón y Tella, La compensación financiera... op. cit., pp. 184-189.
} 
el consumo u operaciones inmobiliarias la pauta será el lugar donde radique el inmueble o donde se realice la operación ${ }^{10}$.

El art. 12.2 LOFCA establece: «Los recargos previstos en el apartado anterior ${ }^{11}$ no podrán configurarse de forma que puedan suponer una minoración en los ingresos del Estado por dichos impuestos ni desvirtuar la naturaleza o estructura de los mismos». Lo que constituye, igual que antes, una invasión de competencias.

De otro lado se puede encontrar el Fondo de Suficiencia Global, que es una garantía del principio de suficiencia que permite asegurar la financiación de la totalidad de las competencias de las Comunidades Autónomas y ciudades con estatuto de autonomía. Respecto a este, el art. 13 LOFCA apunta que su valor inicial podrá ser objeto de revisión en una serie de supuestos en los que, de no modificarse, se produciría un efecto de compensación silenciosa u oculta vertical —en los casos en los que se produzca el traspaso de nuevos servicios o se amplíen o revisen valoraciones de traspasos anteriores y cuando se produzca la cesión de nuevos tributos-.

De todo este elenco o catálogo de principios, artículos y derechos se desprende el principio de interdicción de la compensación oculta o financiación silenciosa ${ }^{12}$.

\section{Descripción doctrinal}

El principio de interdicción de la compensación financiera silenciosa (stille Finanzausgleich) u oculta (versteckte Finanzausgleich) es una creación de la doctrina y la jurisprudencia del Tribunal Constitucional Federal Alemán ${ }^{13}$ (Bundesverfassungsgericht), país donde la teoría de la compensación financiera se encuentra mucho más desarrollada debido a la tradición del sistema federal en Alemania.

La doctrina alemana lo ha definido como: «Las medidas de las corporaciones públicas que, sin derivar de leyes de compensación, tienen un conte-

${ }^{10}$ R. FALCÓN Y TelLA, «El gravamen proporcional de actos jurídicos documentados en los regímenes de concierto y convenio», Revista de Derecho Financiero y de Hacienda Pública, vol. 43, núm. 223 (1993), pp. 15-29.

${ }^{11}$ Las Comunidades Autónomas podrán establecer recargos sobre los tributos del Estado susceptibles de cesión.

12 R. Falcón y Tella, La compensación financiera..., op. cit., pp. 184-189.

13 Hans Pagenkopf, Hans George Ruppe, Sentencia de 18 de febrero de 1952, BVerfG., 117 (131), donde comienza un desarrollo jurisprudencial sobre el principio de solidaridad y el deber de tener en cuenta los intereses del resto de entes territoriales. 
nido jurídico compensatorio, pues afectan indirectamente, de modo positivo o negativo, a la situación financiera de otras corporaciones públicas» ${ }^{14}$.

Constituyen la esencia de este principio aquellas medias adoptadas por las Comunidades Autónomas cuya finalidad excede de la legalmente permitida, aun bajo el manto de sus competencias. Estas medidas tienen una finalidad lucrativa y no compensatoria, alterando la situación financiera de otros niveles de Hacienda — compensación vertical— o del mismo nivel - compensación horizontal - y suponiendo unos gastos o unos menores ingresos para estas.

Por tanto, podemos diferenciar entre aquella compensación que se produce entre distintos niveles de Hacienda (Estado-Comunidades Autónomas, Estado-Entidades Locales, Comunidades Autónomas-Entidades Locales), que conocemos como compensación vertical, y aquella compensación que se produce entre Haciendas del mismo nivel (entre Comunidades Autónomas o entre Entidades Locales), la cual conocemos como compensación horizontal.

Este principio supone, por tanto, un límite claro y preciso al ejercicio de las distintas competencias financieras de que disponen las Comunidades Autónomas, así como al propio sistema de financiación de cada nivel de Hacienda. Se trata de un límite objetivo, en el sentido de que es irrelevante la finalidad que se persiga al ejercer la competencia de que se trate, mientras el resultado sea el menoscabo de los ingresos o el aumento de los gastos ${ }^{15}$.

La primera vez que se tuvo constancia de este principio fue en julio de 1981 a través del Informe de la comisión de expertos sobre financiación de las Comunidades Autónomas, donde se habla del principio de «internalización de costes», una terminología más propia de la ciencia económica que de la jurídica. Este criterio delimita con mucha concisión la naturaleza de las transferencias entre los distintos niveles de Hacienda. Dichas transferencias nunca tendrán por finalidad la cobertura de una insuficiencia, sino que constituirán la contrapartida de los posibles beneficios interjurisdiccionales.

Se puede entender que no se deberán transferir competencias a una entidad territorial sin aportar la suficiente financiación, puesto que, de lo contrario, se caería en un vicio de inconstitucionalidad. Además, sin este principio se enturbiarían aún más las relaciones entre las Comunidades Autónomas, hoy en día en dificultades — como casi desde sus comienzos-,

${ }_{14}$ H. Pagenkopf, Der finanzausgleich in Bundesstaat, Stuttgart, Kohlhammer, 1981, p. 35.

15 R. FALCÓN Y Tella, La compensación financiera..., op. cit., pp. 165-166. 
pero que todavía mantienen su plena vigencia gracias, entre otras cuestiones, a la existencia del principio que aquí analizamos ${ }^{16}$.

Según los datos de los que se dispone, la primera resolución en la que el tribunal llama por su nombre a este principio se encuentra en la Sentencia 1189/2013, de 13 de septiembre, del Tribunal Superior de Justicia (en lo sucesivo, TSJ) de la Comunidad Valenciana, donde, debido al aumento del tipo del Impuesto de Actos Jurídicos Documentados hasta el 2 por 100, se produjo una oleada de recursos solicitando la devolución de ingresos indebidos, alegando, entre otras cuestiones, la inconstitucionalidad de dicho precepto debido al incumplimiento del principio de interdicción de la compensación oculta. Todos fueron desestimados. El tribunal se limitó a establecer una escueta definición y su conexión constitucional ${ }^{17}$.

Como precedente podemos establecer el Auto 253/1992, de 9 de septiembre, del Tribunal Constitucional, por el que se levanta la suspensión de la Ley del Parlamento de las Islas Baleares 12/1991, de 20 de diciembre, reguladora del Impuesto sobre Instalaciones que Incidan en el Medio Ambiente; aquí únicamente se proclama por parte del tribunal la existencia del principio de internalización de costes. Además, posteriormente, en la Sentencia 289/2000, de 30 de noviembre, se declara inconstitucional dicha ley por contravenir el límite del art. 6.3 LOFCA.

Esta sentencia consta de un voto particular que hace hincapié en que los impuestos propios han recibido un cauteloso tratamiento por parte de la Constitución, y especialmente de la LOFCA, lo que deja un estrecho margen de actuación a las Comunidades Autónomas, pese a que el art. 157 CE les ha concedido el «derecho a inventar impuestos»; poder que seguidamente es sometido a límites tan estrechos como para que pueda justificarse la afirmación de que se encuentra, en la práctica, vacío de contenido. La LOFCA, después de reiterar en su art. 6 el reconocimiento de las potestades de las Comunidades Autónomas para establecer sus propios tributos, lo que desarrolla en realidad es un sistema de límites ${ }^{18}$.

Un precedente diferente sería el recurso de inconstitucionalidad núm. 74/1982 contra la Ley 11/1981, de 7 de diciembre, del Parlamento Catalán, y su correspondiente Sentencia 58/1982, de 27 de julio. El cuar-

16 Informe de la comisión de expertos sobre financiación de las Comunidades Autónomas, Madrid, Servicio Central de Publicaciones de la Presidencia del Gobierno, 1981, pp. 8-9.

17 En cuanto que este procede del principio de igualdad, territorialidad, solidaridad, etc., y su significado.

18 J. Zorzona Pérez, «Tributos propios y recargos de las Comunidades Autónomas», Documentación Administrativa, núm. 232-233 (1993), pp. 480-481. 
to argumento en el que el abogado del Estado justifica la inconstitucionalidad de los arts. 7.3 y 9.3 de la ley mencionada dice así: «La facultad de desafectar y disponer de los bienes transferidos que a favor de la Generalidad resulta del art. 7.3 y concordantes de la ley recurrida constituye una forma de financiación adicional de las Comunidades Autónomas a expensas del Estado no tipificada ni en la Constitución ni en la LOFCA ni en los Estatutos y, además, de consecuencias totalmente erráticas, desiguales y arbitrarias, ya que dependerían de la política de desafectación relacionada con el volumen de bienes transferidos en forma que se lesionaría el principio de solidaridad, con lo que resultarían vulnerados los arts. 2 (138) y 158 de la Carta Fundamental, los arts. 2.a) y c) y 5.1 de la LOFCA, y la disposición transitoria tercera, 1, del Estatuto de Cataluña».

Por tanto, se le está presentando al tribunal el principio de interdicción de la compensación financiera oculta. El Tribunal Constitucional no lo rechaza, pero respecto a este asunto concreto afirma que el «incumplimiento de este principio es debido al acatamiento de una obligación constitucional - ya que la transferencia, en este caso de bienes, se debe a una sucesión parcial en el ejercicio de las funciones públicas entre dos entres de esta naturaleza derivada de la reestructuración territorial del Estado— ${ }^{19}$.

\section{CUESTIONES PRÁCTICAS. ANÁLISIS A LA LUZ DE LA DOCTRINA Y LA JURISPRUDENCIA ${ }^{20}$}

\section{Las concesiones, el sistema de financiación de peaje en sombra y el Impuesto sobre Bienes Inmuebles}

El peaje es el instrumento que permite al socio privado concesionario recuperar las inversiones realizadas y los costos futuros de administración, operación y mantenimiento de la infraestructura.

El peaje en sombra (shadow toll o péage fictif) es un método de financiación o un sistema de pago por el cual los usuarios de la carretera no

19 R. FAlCón y Tella, La compensación financiera..., op. cit., p. 188.

$20 \mathrm{Al}$ elenco de casos que vamos a analizar podríamos añadir los ya mencionados en el apartado anterior respecto a la Ley del Parlamento de las Islas Baleares 12/1991, de 20 de diciembre, y a la facultad de desafectar y disponer de los bienes transferidos que a favor de la Generalidad resultan del art. 7.3 y concordantes de la Ley 11/1981 de 7 de diciembre, del Parlamento Catalán, pero su menor interés hace que no sea necesario realizar un análisis más a fondo. 
satisfacen un precio por el aprovechamiento de esta, sino que es la Administración concedente la que paga según se establezca en la concesión, normalmente en función del uso. Es decir, el derecho a circular por la infraestructura de la respectiva vía de comunicación ${ }^{21}$ es gratuito, puesto que será la Administración concedente la que realice el pago del mismo ${ }^{22}$.

El resultado último es la gratuidad del aprovechamiento para los usuarios, la disminución del endeudamiento de la Administración concedente y llamar peaje a un supuesto ficticio en el que, en puridad, no existe ${ }^{23}$.

Respecto al Impuesto sobre Bienes Inmuebles (en adelante, IBI), estos contratos están sujetos al mismo, puesto que cumplen el hecho imponible enunciado en el art. 61.1 TRLRHL gravando al concesionario. Además, concurren los dos elementos necesarios, un derecho y un bien inmueble (aunque este último ha sido más controvertido) ${ }^{24}$.

El problema se plantea en relación con el art. 61.5.a) del Texto Refundido de la Ley Reguladora de las Haciendas Locales (en adelante, TRLRHL): «5. No están sujetos a este impuesto: a) Las carreteras, los caminos, las demás vías terrestres y los bienes del dominio público marítimo-terrestre e hidráulico, siempre que sean de aprovechamiento público y gratuito para los usuarios».

La controversia existente se debe al hecho de que las Sentencias del Tribunal Supremo de 21 de enero de 1999 y de 22 de julio de 2000 -las primeras en pronunciarse al respecto- declaraban que una central hidroeléctrica no se consideraba de aprovechamiento gratuito, puesto que el concesionario era una entidad privada con ánimo de lucro. Además, la Sentencia del TS de 7 de junio de 2006 declaraba que el hecho de que exista una concesión administrativa a favor de una entidad mercantil regida por el ánimo de lucro eliminaba toda posibilidad de gratuidad.

La Audiencia Nacional, en su Sentencia de 2 de diciembre de 2008, analizaba el caso del peaje en sombra y concluía que no podía calificarse de gratuito, debido a que era una empresa con un legítimo ánimo de lucro que recibe de la Comunidad de Madrid una subvención, de la que una parte será beneficio.

\footnotetext{
${ }^{21}$ Carreteras, canales de navegación, puentes, túneles, etcétera.

22 Bélgica, en la década de los sesenta, fue el primer país en ponerlo en práctica a través de una empresa pública.

23 B. García CARRetero, «La concesión de obra pública en el ámbito local. Especial referencia al IBI», Quincena Fiscal, núm. 4 (2011), pp. 61-63.

${ }_{24}$ Puesto que había que debatir si jurídicamente existía una concesión administrativa sobre un inmueble antes de que este se construyese.
} 
Pese a la postura continuista de los tribunales, no faltaban voces en el ámbito doctrinal reclamando lo contrario, puesto que el coste de la obra se sufraga vía impuestos, no a través del cobro de un precio por su aprovechamiento.

Por tanto, en lo que aquí nos incumbe, la sujeción de este tipo de autopistas al IBI supone una transferencia de fondos desde el ente público concedente al ayuntamiento, al ser este quien lo recauda, y la exigencia del ayuntamiento supone inevitablemente un mayor gasto para el Estado o la Comunidad Autónoma ${ }^{25}$.

Otras opiniones, como la del Instituto de Estudios Fiscales, entienden que, según la memoria que acompañaba al proyecto de Ley Reguladora de las Haciendas Locales, «la exceptuación fiscal descomedida no solo arriesga la suficiencia de un impuesto, sino que también compromete la flexibilidad impositiva e impide atender a la financiación de los servicios públicos fundamentales que el propio desarrollo de la sociedad demanda imperativamente y, en la esfera local, ha de sufragar la Hacienda de los municipios». Por otro lado, el «posible problema administrativo que las exenciones tributarias pudieran plantear, pues lastran la gestión de cualquier sistema fiscal, complica las labores recaudatorias con un coste obvio y, por tratarse de un derecho excepcional, deben nacer y administrarse con exquisita disciplina en el otorgamiento» ${ }^{26}$. La exceptuación fiscal debe extenderse también a la no sujeción de los impuestos locales, en aras de no mermar la potencia recaudatoria de dichos impuestos; de lo contrario, esa pérdida recaudatoria debería sostenerse vía transferencias del Estado o de las Comunidades Autónomas correspondientes.

Una vez planteados ambos contrapuntos, debemos destacar el requisito de la gratuidad y su sentido, es decir, si debe venir referido única y exclusivamente a los usuarios del servicio o destinatarios de la obra, o si, por el contrario, debe venir referido a una consideración global del mismo. Ciertamente, la valoración global en la mayoría de los casos nos conducirá a negar la presencia de ese requisito, ya que siempre cabe apreciar la presencia de un cierto ánimo de lucro. Además, como ya hemos dicho, la sujeción de este tipo de concesiones supone una transferencia de fondos, lo que quiebra el principio de interdicción de la compensación financiera silenciosa u oculta, ya que el concesionario repercutiría en su propues-

\footnotetext{
25 B. García CarRetero, «La concesión de obra pública...», op. cit., pp. 60- 66.

26 I. Merino Jara, «Las centrales hidroeléctricas y el Impuesto sobre Bienes Inmuebles», Jurisprudencia Tributaria Aranzadi, vol. II (1998), pp. 19-25.
} 
ta económica el importe de dicho impuesto, provocando que el auténtico pagador del gravamen sea el ente público concedente ${ }^{27}$.

Finalmente, el Tribunal Supremo anuló la Sentencia de 2 de diciembre de 2008 de la Audiencia Nacional al no haber sido emplazada personalmente para comparecer la Comunidad de Madrid, por lo que tuvo que pronunciarse la Audiencia de nuevo en la Sentencia de la Sala de lo Contencioso de 6 de marzo de 2014.

El letrado de la Comunidad invocó la consulta vinculante 2358/2009, de 22 de octubre, en la que se cuestionaba el tratamiento de las autovías de peaje en la sombra en el Impuesto sobre Bienes Inmuebles. En dicha consulta se estima que se produce un «uso gratuito» de la carretera, explicando que:

«Conforme al art. 3.1 del Código Civil al que se remite el art. 12.1 de la Ley 58/2003, de 17 de diciembre, General Tributaria, "se interpretarán según el sentido propio de sus palabras", por lo que el término gratuito ha de quedar referido necesariamente al aprovechamiento del bien, sin coste monetario para los usuarios del mismo, en este caso, de la autovía objeto de consulta. Por tanto, debemos concluir que, con independencia de que la Administración Pública remunere a la empresa concesionaria mediante el llamado "peaje en la sombra", concurren los requisitos para la consideración de bien no sujeto al Impuesto sobre Bienes Inmuebles, ya que el bien inmueble en cuestión, objetivamente considerado, es objeto de una utilización pública (no existe limitación en función del tipo de usuario) y gratuita (sin pago por su utilización) por parte de los usuarios».

El tribunal decidió acogerse a dicha consulta y fundamentar su decisión de cambiar de criterio en la modificación introducida por el art. 14.2 de la Ley 16/2012, de 27 de diciembre, respecto al art. 61.5.a), y estimó la exención de dicha carretera financiada con el sistema de peaje en sombra.

\section{Las concesiones y el Impuesto sobre Trasmisiones Patrimoniales Onerosas}

Las notas características de la concesión ${ }^{28}$ no se han visto recogidas en la legislación; se ha fijado de forma prioritaria el desplazamiento del ries-

27 B. García CARRETERO, «La concesión de obra pública...», op. cit., pp. 65-66.

${ }_{28}$ Transferencia de facultades originariamente públicas y desplazamiento patrimonial al particular. 
go al concesionario ${ }^{29}$. Así, la concesión de obra pública se ha considerado como una simple alternativa para financiar la realización de infraestructuras en colaboración con el sector privado, con absoluta independencia del término concesión, en el sentido jurídico del mismo ${ }^{30}$.

Dentro del concepto comunitario de obras públicas se incluyen dos fórmulas de colaboración público-privadas en lo que aquí nos incumbe, la Iniciativa de Financiación Privada (en adelante, IFP) ${ }^{31}$ es aquella donde la tarea del socio privado consiste en realizar y gestionar una infraestructura para la Administración. La remuneración del socio privado no adopta la forma de cánones abonados por los usuarios de la obra o el servicio, sino de pagos periódicos realizados por el socio público. Dichos pagos pueden ser fijos, pero también pueden calcularse de manera variable.

En este modelo emerge la posibilidad de que no exista ninguna transferencia al concesionario de facultades originariamente públicas; en tal caso no se devengará el Impuesto sobre Transmisiones Patrimoniales Onerosas (en adelante, TPO), pues no hay ningún desplazamiento patrimonial desde el ente público en favor del concesionario, lo que hay es una prestación de servicios y/o ejecución de obra, con la peculiaridad de que la contraprestación no consiste en una cantidad fija, sino variable ${ }^{32}$.

En el contrato de colaboración entre el sector público y el privado la remuneración del socio privado no se adaptará a cantidades abonadas por los usuarios, sino que se efectuará mediante pagos por parte de la Administración concedente (o socio público) en función de una serie de variables que incorporarán el riesgo: frecuencia de uso, disponibilidad, etcétera ${ }^{33}$.

Añadir que, al igual que las Comunidades Autónomas no pueden cobrar una tasa por la utilización del dominio público de un nivel territorial distinto al suyo o por la prestación de un servicio de competencia distinta a la suya propia —es decir, municipal o estatal—, tampoco podrán exigir un impuesto sobre las concesiones otorgadas para explotar servicios,

\footnotetext{
29 Arts. 7, 225, 229 y 236 LCSP, entre otros.

30 R. FAlCón y Tella, Régimen fiscal de la concesión de obra pública, Madrid, Marcial Pons, 2006, pp. 24-25.

31 Introducido por el gobierno conservador de John Mayor en 1992 en el Reino Unido, utilizado previamente en los años setenta en Bélgica para financiar carreteras e inspirador del modelo betreibermodell en Alemania.

32 R. Falcón y Tella, Régimen fiscal de la concesión de obra..., op. cit., pp. 28-32.

33 J. M. Almudí Cid, «La tributación indirecta del contrato de concesión de obras públicas a la luz de la Ley 30/2007, de Contratos del Sector Público, y de la reciente doctrina de la dirección general de tributos», Crónica Tributaria, núm. 132 (2009), pp. 73-74.
} 
utilización privativa o aprovechamiento especial de bienes demaniales de los que la Comunidad Autónoma sea competente ${ }^{34}$.

En este caso se produciría, y se está produciendo, una transferencia de fondos desde el ente público concedente a la Comunidad Autónoma, que es la encargada de recaudar el TPO, lo que quiebra el principio de interdicción de la compensación financiera silenciosa u oculta. La exigencia del impuesto supone inevitablemente un mayor gasto para el Estado o el ayuntamiento. En el supuesto de que fuese la propia Comunidad Autónoma la concedente tampoco tendría sentido, puesto que supondría para ella un mayor gasto, que luego recuperaría vía impuestos (concretamente, TPO) ${ }^{35}$.

Aquí se produce el curioso suceso de que no es la legislación de la Comunidad Autónoma la que permite la transferencia de fondos, sino que es la legislación estatal en materia de cesión de $\operatorname{tributos}^{36}$ la que dispone que serán las Comunidades Autónomas las que recauden dicho impuesto, que se convertirá en un tributo cedido.

\section{Tipos incrementados del Impuesto sobre los Actos Jurídicos Documentados en el caso de renuncia al Impuesto sobre el Valor Añadido}

En relación con el Impuesto sobre Actos Jurídicos Documentados (en adelante, AJD), este grava una serie de documentos: notariales (escrituras, actas y testimonios), mercantiles (letras de cambio y documentos con función de giro) y administrativos (anotaciones preventivas de embargo y rehabilitaciones o transmisiones de grandezas o títulos nobiliarios).

Dentro del apartado de documentos notariales hay dos tipos de gravamen: cuota fija y cuota variable o gravamen proporcional.

Respecto a las compatibilidades ${ }^{37}$, se puede colegir que nunca podrá gravarse el Impuesto sobre el Valor Añadido (en adelante, IVA), AJD ni TPO al mismo tiempo, por tanto, en algunos casos pagaremos AJD e IVA o TPO.

El IVA se aplicará cuando quien transmita sea empresario o profesional, mientras que se aplicará el TPO cuando el transmitente sea un par-

34 R. FALCÓN Y TELLA, «Dos consecuencias del principio de interdicción...», op. cit., p. 8.

35 R. Falcón y Tella, Régimen fiscal de la concesión de obra..., op. cit., pp. 33-34.

36 Art. 25 de la Ley 22/2009, por la que se regula el sistema de financiación de las Comunidades Autónomas de régimen común y ciudades con Estatuto de Autonomía.

37 Arts. 20.Uno, apartados 22..$^{\circ}$ y $23 .^{\circ}$, y 22.Dos de la Ley 37/1992 y art. 7 del Real Decreto Legislativo 1/1993. 
ticular. La principal diferencia entre ambos estriba en que, por una parte, el IVA es deducible por el empresario, por lo que no sería un coste, mientras que el TPO sí lo sería.

Las operaciones realizadas por empresarios en el ejercicio de su actividad empresarial o profesionales en el ejercicio de su actividad profesional como norma general no estarán sujetas a TPO, sino a IVA; por tanto, son totalmente incompatibles.

Esta regla no tiene excepciones en el caso de las operaciones sujetas a IVA - aunque sea como consecuencia de la renuncia o exención-. Sin embargo, tratándose de operaciones exentas de IVA o no sujetas, excepcionalmente se aplica el TPO; concretamente debemos destacar el caso de las entregas de inmuebles exentas de IVA en que se renuncie a la exención, como, por ejemplo, las entregas de terrenos rústicos y las segundas entregas de edificaciones.

Algunas Comunidades Autónomas han establecido tipos reducidos en las transmisiones de inmuebles exentas de IVA y en los supuestos de segundas y ulteriores entregas de edificaciones. Estas exenciones del IVA son renunciables $y$, por tanto, en la práctica, se puede elegir entre pagar IVA (a veces acompañado de AJD) o TPO. Con esto se pretende desanimar a los sujetos a renunciar a la exención del IVA, reduciendo el TPO si no se renuncia e incrementando el impuesto de AJD en el caso de que el sujeto renuncie a la exención del IVA ${ }^{38}$.

El resultado final es claro: una institución como la renuncia a la exención del IVA, cuyo objetivo es garantizar la neutralidad del impuesto en las operaciones económicas y no beneficiar al sujeto pasivo ${ }^{39}$, se acaba distorsionando por culpa de criterios ajenos al IVA, ya que se establecen criterios que suponen una interferencia en el correcto funcionamiento del impuesto estatal ${ }^{40}$.

Los datos de la siguiente tabla, recogidos a 8 de mayo de 2018, son los tipos de gravamen de TPO cuando no se renuncia a la exención de IVA y de AJD si se renuncia a la exención de IVA en las distintas Comunidades Autónomas y en el régimen general ${ }^{41}$ :

38 R. Falcón y Tella, G. De la Peña y M. A. Martínez Lago (coords.), Sistema fiscal español (impuestos estatales, autonómicos y locales), 7. . ed., Madrid, Iustel, 2006, pp. 200 y ss.

39 J. Aspichueta Grijelmo. «La renuncia a las exenciones inmobiliarias del IVA», Carta Tributaria, núm. 181 (1993), p. 3.

${ }^{40}$ V. Ruiz Almendral, «Diez preguntas sobre los impuestos cedidos», Quincena Fiscal, núm. 17 (2004), p. 46.

${ }^{41}$ Datos recogidos de los correspondientes reales decretos legislativos de cada Comunidad Autónoma publicados en sus correspondientes boletínes oficiales. 


\begin{tabular}{|l|c|c|}
\hline & TPO (\%) & $A J D(\%)$ \\
\hline Régimen general & 6,0 & 0,5 \\
\hline Andalucía & - & 2,0 \\
\hline Aragón & 3,0 & 2,0 \\
\hline Asturias & 2,0 & 1,5 \\
\hline Baleares & 4,0 & 2,0 \\
\hline Canarias & - & 1,0 \\
\hline Cantabria & 4,0 & 1,5 \\
\hline Castilla-La Mancha & 4,0 & 2,5 \\
\hline Castilla y León & - & 2,0 \\
\hline Cataluña & - & 2,5 \\
\hline Comunidad de Madrid & - & 1,5 \\
\hline Comunidad Valenciana & - & 2,0 \\
\hline Extremadura & 3,0 & 2,0 \\
\hline Galicia & - & 2,0 \\
\hline La Rioja & - & 1,5 \\
\hline Murcia & - & 2,5 \\
\hline Navarra & - & 1,0 \\
\hline Álava & - & - \\
\hline Guipúzcoa & - & - \\
\hline Vizcaya & & - \\
\hline
\end{tabular}

Respecto a las reglas sobre incompatibilidad entre el gravamen proporcional de AJD y otros impuestos, es importante destacar que han de interpretarse necesariamente en su contexto actual, lo que permite afirmar la incompatibilidad con el IVA también, aunque no se recoja expresamente en la ley, puesto que la normativa del IVA trata de imponer un impuesto indirecto único e inmediatamente deducible.

Además, al contrario de lo que pasaba en el apartado anterior, aquí la responsabilidad se debe imputar a las Comunidades Autónomas, puesto que son ellas las responsables de legislar al respecto; también es cierto que por cesión estatal, lo que no ha ayudado a aumentar la problemática de este impuesto ${ }^{42}$.

42 R. FALCÓN y TELlA, «El extravagante ejercicio de las competencias autonómicas en relación con los tipos de AJD», Quincena Fiscal, núm. 2 (2002), p. 6. 


\section{Inclusión en la prorrata, dentro del Impuesto sobre el Valor Añadido, de las subvenciones y su relación con la Sexta Directiva ${ }^{43}$}

La reforma de la Ley del IVA introducida por la Ley 66/1997, de 30 de diciembre, introdujo en el denominador, a efectos de prorrata, las subvenciones, provocando una minoración del IVA deducible y un enfrentamiento con los arts. 17, apartados 2 y 5, y 19 de la Directiva 77/388/CEE del Consejo, de 17 de mayo de 1977 (Sexta Directiva), como años más tarde declararía el Tribunal de Justicia de las Comunidades Europeas (en adelante, TJCE). El resultado de esta inclusión tenía como corolario que la cuantía de la subvención, o al menos su incidencia económica efectiva, variase en función de la opción que hubiese adoptado el legislador en relación con la inclusión o no de dichas subvenciones.

Por tanto, no solo ninguna subvención que provenga directa o indirectamente del presupuesto comunitario debería incluirse a efectos de prorrata, sino que tampoco deberían hacerlo las subvenciones otorgadas o financiadas con fondos de las Comunidades Autónomas o corporaciones locales, puesto que esto supondría una quiebra del principio constitucional de compensación financiera silenciosa, ya que significaría aumentar la necesidad de gasto para mantener el mismo nivel efectivo de subvención.

Parecía que habíamos elegido el camino adecuado al eliminar las subvenciones financiadas con cargo al Fondo Europeo de Orientación y Garantía Agrícola a través de la Ley 9/1998, de 21 de abril, pero no fue así, tuvimos que esperar hasta la reforma de 2006 para solucionar este problema ${ }^{44}$.

Respecto a la inclusión de las subvenciones otorgadas o financiadas con fondos de las Comunidades Autónomas o corporaciones locales, esto provoca un desequilibrio financiero, ya que la inclusión de las subvenciones ha provocado que estas tengan que aumentar las dotaciones presupuestarias en el importe del IVA no deducible o aumentar el precio de los respectivos servicios públicos. Este aumento en la dotación presupuestaria ha derivado, como era obvio, en un aumento de su déficit público o en un aumento de la presión fiscal.

Esto no se produce respecto a las empresas del Estado, puesto que al ser este quien recauda el impuesto el efecto es neutro. Este fenómeno de

${ }^{43}$ Directiva derogada, ahora Directiva 2006/11/CE.

${ }^{44}$ R. FALCÓN Y TELLA, «La norma excepcional por la Ley 8/1998 para las subvenciones del FEOGA y la posibilidad de extender la misma a las subvenciones autonómicas y locales», Quincena Fiscal, núm. 12 (1998), pp. 5-8. 
vasos comunicantes ${ }^{45}$ no se produce tampoco con las Comunidades Autónomas ni con las corporaciones locales ${ }^{46}$.

En consonancia con lo que se comentaba antes, no fue hasta la Ley 3/2006, de 29 de marzo, modificadora de la Ley del IVA, cuando se suprimieron totalmente las subvenciones no por obra y gracia del legislador, sino porque el TJCE declaró en la Sentencia de 6 de octubre de 2005 (asunto C-204/03) que el Reino de España había incumplido las obligaciones que le incumben en virtud del Derecho comunitario vulnerando la Sexta Directiva.

En dicha sentencia se dice que «las disposiciones del art. 19, apartado 1 , segundo guión, relativas a las subvenciones que no sean las enunciadas en el art. 11, parte A, apartado 1, letra a), de la Sexta Directiva, esto es, a las subvenciones que no estén vinculadas al precio del bien o servicio suministrado y que no formen parte de la base imponible del IVA, deben ser interpretadas a la luz del art. 17, apartado 5. Pues bien, este último precepto solo se refiere a los sujetos pasivos mixtos, como se desprende expresamente de su tenor literal. De ahí que el citado art. 19, apartado 1, segundo guión, al no tratarse de una excepción aplicable a los sujetos pasivos mixtos y totales, únicamente permite limitar el derecho a deducción, mediante la toma en consideración de las subvenciones antes definidas, en el caso de los sujetos pasivos mixtos.

Por consiguiente, la norma general contenida en la Ley 37/1992, que amplía la limitación del derecho a deducción mediante su aplicación a los sujetos pasivos totales, introduce una restricción mayor que la prevista expresamente en los arts. 17, apartado 5, y 19 de la Sexta Directiva e incumple las disposiciones de dicha Directiva» ${ }^{47}$.

\section{Apuntes al régimen de concierto y convenio del País Vasco y Navarra}

El régimen de concierto y convenio supone un cierto federalismo en el ámbito fiscal no merecedor de crítica en tanto en cuanto sus coordenadas no trastornen los objetivos de la política interior que el Estado debe

${ }^{45}$ Por el cual a la empresa estatal que ingresa más IVA se le reinserta de nuevo incrementando su dotación presupuestaria en el mismo importe del IVA en exceso que ha recaudado.

${ }^{46}$ A. DuRÁn-SindReu BuxAdÉ, «IVA y competencia desleal del Estado», Jurisprudencia Tributaria Aranzadi, núm. 2 (2005), pp. 9-10.

47 STJCE de 6 de octubre de 2005, asunto C-204/03. 
imponerse para que cada Comunidad Autónoma integrada en él contribuya igualitariamente a las cargas del progreso social ${ }^{48}$.

Podríamos destacar una serie de casos donde existe una duda más que razonable sobre si existe una transferencia de fondos que suponga una compensación oculta:

1. Reducción del Impuesto sobre Actos Jurídicos Documentados y su relación con la libre elección de notario. El problema surgió cuando a lo largo de los años 1990 a 1992 los Territorios Históricos de Vizcaya, Álava y Guipúzcoa y la Comunidad Foral de Navarra aprobaron una reducción de los AJD, en su modalidad proporcional, de hasta el 0,1 por $100^{49}$. Las leyes correspondientes establecieron como punto de conexión que las escrituras, actas o testimonios notariales se autorizaran o se otorgaran en territorio vasco o navarro ${ }^{50}$.

El acceso a estos tipos ventajosos quedaba abierto a la discrecionalidad de cualquier ciudadano del Estado que se acogiera a la libertad de elección de notario. Esto formaba, en el propio ámbito nacional, paraísos fiscales monográficos de acceso discrecional ${ }^{51}$.

El resultado final es la deslocalización de otorgamientos de los actos documentados gravados y sus consiguientes liquidaciones y recaudaciones, trayendo como consecuencia una compensación financiera silenciosa u oculta, prohibida por el ordenamiento constitucional. La libertad de elección de notario origina esta compensación silenciosa, provocando una minoración en la recaudación de las Comunidades Autónomas de régimen común, principalmente las limítrofes con las Comunidades Forales ${ }^{52}$.

El establecimiento de tipos reducidos, el derecho a la libertad de elección de notario y el punto de conexión previsto en el Concierto y Conve-

48 J. L. MezQuita del CACHO, «Las diferencias forales de fiscalidad sobre actos jurídicos documentados y la libre elección de notario», Quincena Fiscal, núm. 21 (1993), pp. 13-28.

49 Art. 79.1 de la Norma Foral del Territorio Histórico de Vizcaya, de 21 de diciembre de 1990; art. 6 del Decreto Foral normativo de la Diputación Foral de Álava 43/1991, de 29 de enero; disposición adicional segunda de la Norma Foral de Guipúzcoa 10/1991, de 4 de noviembre, y la disposición adicional decimotercera de la Ley Foral 6/1992, de 14 de mayo.

50 R. FALCÓN Y TELLA, «El gravamen proporcional de actos jurídicos documentados...», op. cit., pp. 15-29.

51 J. L. MezQuita DEL CACHO, «Las diferencias forales de fiscalidad sobre actos jurídicos documentados...», op. cit., pp. 14-15.

52 R. FALCÓN Y TELLA, «El gravamen proporcional de actos jurídicos documentados...», op. cit., pp. 15-29. 
nio respecto al gravamen de AJD son las variables a tener en cuenta. Por su entronque constitucional, para restringir el derecho a la libertad de notario hace falta una ley y un motivo suficiente. $\mathrm{Ni}$ en el Concierto ni en el Convenio establecen límites a la modificabilidad del tipo. Para encontrar dónde radica la situación de compensación financiera oculta debemos irnos al punto de conexión previsto en el Concierto y el Convenio ${ }^{53}$.

2. ${ }^{\circ} \quad$ Especial referencia al Impuesto sobre Sociedades en el País Vasco. El art. 14 de la Ley 12/2002, de 23 de mayo, del Concierto Económico, sujetaba a la normativa foral en materia de Impuesto sobre Sociedades a las empresas con domicilio fiscal en el País Vasco que tuvieran un volumen de operaciones inferior a seis millones de euros, cualquiera que fuera el lugar donde realizaran sus actividades. Se establecía un punto de conexión que permitía gravar en la Comunidad Autónoma del País Vasco rentas generadas fuera de su territorio, lo que rompía la neutralidad del tributo y la adecuación de recursos.

Para que operase esta sujeción no se exigía el traslado de sus instalaciones productivas, sino el de su domicilio fiscal, es decir, su domicilio social, siempre que en él estuviera efectivamente centralizada su gestión administrativa y la gestión de su negocio. La normativa actual se ha corregido haciendo más difícil sujetarse a la normativa foral.

La Sentencia del Tribunal Supremo de 9 de diciembre de 2004 declaró nulos determinados preceptos de la Norma Foral reguladora del Impuesto sobre Sociedades, entre ellos el tipo de gravamen. Además, a raíz de esta sentencia se suspendieron cautelarmente por el TSJ del País Vasco las normativas promulgadas en 2005 en lo referente, entre otros aspectos, al tipo general de gravamen aplicable del 32,6 por $100^{54}$.

3. Normas forales que pueden implicar compensación oculta o silenciosa a raíz de la sentencia del Ttibunal de Justicia de la Unión Europea (en adelante, TJUE) en el caso Azores ${ }^{55}$. El tribunal señaló en dicha sentencia que: «Determinadas normas forales adoptadas por los territorios históricos pueden implicar compensaciones ocultas en sectores como la Seguridad Social o la garantía por parte del Estado español de un servicio público

\footnotetext{
53 Ibid., pp. 228 y 229.

${ }^{54}$ Comentarios sobre los efectos derivados de la declaración de nulidad de determinados preceptos de las normas forales vascas reguladoras del impuesto de sociedades, Consejo General de Economistas, 2007, disponible en bttps://economistas.es/Contenido/REA/CircularInformativa/070321_circular_para_auditores_pdf (consultado el 14 de abril de 2017).

55 Sentencia del TJUE de 11 de septiembre de 2008, asuntos acumulados C-428/06 a C-434/06.
} 
mínimo, o incluso en el funcionamiento del Fondo de Compensación Interterritorial, como afirma en particular la Comisión».

A este respecto, el TSJ del País Vasco, en Sentencia de 22 de diciembre de 2008, no alberga dudas de la autonomía económica de los territorios históricos al señalar que: «El País Vasco opera como fiscalmente responsable de sus políticas en materia tributaria, asumiendo las repercusiones que de una menor recaudación puedan derivarse en la limitación del gasto público en servicios para la comunidad e infraestructuras de su competencia, sin que existan previsiones normativas específicas en el sistema acerca de que el déficit fiscal hipotético que pudiera seguirse de una menor recaudación fuese soportado o subvencionado por los poderes públicos centrales o por otras regiones» ${ }^{56}$.

Parte de la doctrina ha entendido que el TSJ del País Vasco debería haber analizado con más detenimiento el sistema de financiación vasco, clarificando si dicho sistema determinaba la asunción de los efectos económicos de las rebajas fiscales por las provincias forales que las establecieron o si, por el contrario, existía una compensación encubierta en la determinación del cálculo del cupo $^{57}$.

\section{CONCLUSIONES}

Ha quedado suficientemente probado, como se puede vislumbrar entre la maraña de artículos y principios que se enuncian en la Constitución, cómo el principio de interdicción de la compensación financiera silenciosa u oculta es consecuencia directa de los principios de solidaridad, igualdad, territorialidad, coordinación de las competencias legislativas y capacidad económica. Aunque las implicaciones constitucionales y legales de los distintos asuntos que se han tratado han sido variopintas.

La importancia de este principio en la esfera pública del sistema de compensación y financiación es capital: sin un orden establecido y firme, la figura de la compensación quedaría desvirtuada, vaciando de contenido otras competencias y funciones, como las que tiene el Fondo de Compensación Interterritorial o la participación en los tributos del Estado

56 Á. J. DEL Blanco García, «Prohibición de las ayudas otorgadas por entes subcentrales», Diario La Ley, núm. 8.134 (2013), pp. 8-10.

57 V. Ruiz Almendral y R. Martínez Caballero, «ंTodo debe cambiar para que todo siga igual? El irresuelto problema de la incompatibilidad del concierto económico vasco y el Derecho comunitario», Anuario Jurídico de La Rioja, núm. 13 (2008), pp. 115-146. 
tanto de las Comunidades Autónomas como de los municipios. El sistema de compensación se debe encargar de asegurar la suficiencia de recursos de las Haciendas territoriales y locales, y de salvaguardar los desequilibrios entre ellas dentro del orden legal. Por ello deben examinarse con el mayor rigor posible aquellas medidas que, por su objeto inmediato, parecen dirigidas a asegurar a una parte del territorio beneficios o ventajas a expensas de otros.

Los tribunales han acogido este principio, aunque fundamentalmente ha sido aceptado el concepto, es decir, hay una amplia jurisprudencia sobre la transferencia de fondos que reconoce su inconstitucionalidad, pero pocos son los casos en los que se habla concretamente del principio de interdicción de la compensación financiera silenciosa u oculta o de su homólogo en terminología económica: internalización de costes.

Es de subrayar que España se ha enfrentado reiteradas veces a este problema y ha logrado afrontarlo con relativo éxito, pero siempre o casi siempre en base a otros principios constitucionales, los cuales parecen estar más valorados por los tribunales que este. También han sido pocos los casos en los que los tribunales han tenido la valentía de expresar con claridad que cierta normativa incumplía este principio y se estaba produciendo una transferencia de fondos; ha sido habitual observar fórmulas condicionales en la jurisprudencia tanto española como europea.

No es permisible que por culpa de criterios ajenos ciertas medidas acaben distorsionando el correcto funcionamiento de la financiación, la compensación y los impuestos. Se ha visto cómo un gran elenco de impuestos se puede ver afectado por este vicio: el IVA, el ITP, el AJD, el IS y el IBI, aunque la lista podría ampliarse, ya que los cambios en el punto de conexión o en otros criterios pueden desvirtuar la finalidad de los tributos. Debemos recordar que es indiferente el objetivo que se persiga siempre que el resultado final sea la distorsión del sistema de compensación.

Es cierto que es una materia extremadamente compleja, y asegurar que una medida está ocasionando un desajuste es una ardua tarea que en muchos casos es más económica que jurídica, puesto que el análisis legal proporciona un soporte teórico, mientras que el estudio del impacto económico lo dota del necesario soporte práctico. Pese a todo, hay ocasiones en las que el incumplimiento de este principio es flagrante (por ejemplo, en el caso de los tipos de gravamen reducidos de TPO cuando no se renuncia a la exención de IVA e incrementados de AJD cuando se renuncia a la exención de IVA). Se está primando una opción, beneficiosa para una de las partes, y ocasionando un perjuicio a la Hacienda estatal. 
Respecto a la problemática con los Territorios Históricos y Navarra, la complejidad aumenta exponencialmente, puesto que junto a la normativa estatal se suma la normativa foral y los derechos propios de estas Comunidades, que bastantes problemas nos han ocasionado, produciendo una tensión constante entre el gobierno central y los respectivos gobiernos autonómicos.

Este principio se encuentra en una fase inicial de desarrollo. No sabemos cuál puede ser su progreso futuro, pero sí parece evidente que se debe estudiar con detalle la experiencia de otros países, principalmente Alemania, cuyos tribunales, políticos y juristas han hecho un esfuerzo en esta materia.

\section{BIBLIOGRAFÍA}

AAVV, Informe de la comisión de expertos sobre financiación de las Comunidades Autónomas, Madrid, Servicio Central de Publicaciones de la Presidencia del Gobierno, 1981.

Almudí CID, J. M., «La tributación indirecta del contrato de concesión de obras públicas a la luz de la Ley 30/2007, de Contratos del Sector Público, y de la reciente doctrina de la dirección general de tributos», Crónica Tributaria, núm. 132 (2009), pp. 63-81.

Aspichueta Grijelmo, J., «La renuncia a las exenciones inmobiliaria del IVA», Carta Tributaria, núm. 181 (1993), pp. 1-8.

Blanco García, Á. J. del, «Prohibición de las ayudas otorgadas por entes subcentrales», Diario La Ley, núm. 8.134 (2013).

Comentarios sobre los efectos derivados de la declaración de nulidad de determinados preceptos de las normas forales vascas reguladoras del Impuesto de Sociedades, Consejo General de Economistas, 2007, disponible en https://economistas.es/ Contenido/REA/CircularInformativa/070321_circular_para_auditores_pdf (consultado el 14 de abril de 2017).

DurÁn-SindReu BuXAdÉ, A., «IVA y competencia desleal del Estado», Jurisprudencia Tributaria Aranzadi, núm. 2 (2005), pp. 9-10.

FALCón Y Tella, R., La compensación financiera interterritorial, Madrid, Congreso de los Diputados, 1986.

- «El gravamen proporcional de actos jurídicos documentados en los regímenes de concierto y convenio», Revista de Derecho Financiero y de Hacienda Pública, vol. 43, núm. 223 (1993), pp. 15-42.

— «La norma excepcional por la Ley 8/1998 para las subvenciones del FEOGA y la posibilidad de extender la misma a las subvenciones autonómicas y locales», Quincena Fiscal, núm. 12 (1998), pp. 5-8. 
- «El extravagante ejercicio de las competencias autonómicas en relación con los tipos de AJD», Quincena Fiscal, núm. 2 (2002), pp. 5-7.

- Régimen fiscal de la concesión de obra pública, Madrid, Marcial Pons, 2006.

- «Dos consecuencias del principio de interdicción constitucional de la compensación financiera silenciosa u oculta (Stille Finanzausgleicht) en el ITPAJD: las concesiones y los tipos incrementados de AJD en caso de renuncia a la exención de IVA», Quincena Fiscal, núm. 7 (2007), pp. 5-8.

Falcón y Tella, R.; De la Peña Velasco, G., y Martínez Lago, M. A. (coords.), Sistema fiscal español (impuestos estatales, autonómicos y locales), 7." ed., Madrid, Iustel, 2006.

Fernández Junquera, M., «Límites de las Cortes Generales al establecimiento de tributos por las Comunidades Autónomas», en Las Cortes Generales, vol. II, Madrid, Ministerio de Economía y Hacienda-Instituto de Estudios Fiscales, 1987, pp. 1023-1054.

García CARREtero, B., «La concesión de obra pública en el ámbito local. Especial referencia al IBI», Quincena Fiscal, núm. 4 (2011), pp. 53-73.

LASARTE, J., Manual general de Derecho financiero, t. IV, Sistema tributario autonómico y local, Granada, Comares, 1996.

MERINO JARA, I., «Las centrales hidroeléctricas y el Impuesto sobre Bienes Inmuebles», Jurisprudencia Tributaria Aranzadi, vol. II (1998), pp. 19-25.

Mezquita del CACHO, J. L., «Las diferencias forales de fiscalidad sobre actos jurídicos documentados y la libre elección de notario», Quincena Fiscal, núm. 21 (1993), pp. 13-28.

Muñoz Machado, S., Derecho público de las Comunidades Autónomas, t. I, 2.a ed., Madrid, Iustel, 2007.

Pagenkopf, H., Der finanzausgleich im Bundesstaat, Stuttgart, Kohlhammer, 1981.

Palomar, A., y Fuentes, J., Práctico administrativo (ibook), Vlex, 2014, apartado «Administración pública, régimen jurídico y relación entre Administraciones Públicas».

Ruiz Almendral, V., «Diez preguntas sobre los impuestos cedidos», Quincena Fiscal, núm. 17 (2004), pp. 39-48.

Ruiz Almendral, V., y Martínez Caballero, R., «¿Todo debe cambiar para que todo siga igual? El irresuelto problema de la incompatibilidad del concierto económico vasco y el Derecho comunitario», Anuario Jurídico de La Rioja, núm. 13 (2008), pp. 115-150.

Varona Alabern, J. E., 25 años de financiación autonómica, Santander, Universidad de Cantabria, 2005.

Zorzona Pérez, J., «Tributos propios y recargos de las Comunidades Autónomas», Documentación Administrativa, núm. 232-233 (1993), pp. 477-487. 